\begin{abstract}
Armando Partida Tayzán
Licenciado en Filología Rusa en Moscú y Doctor en Literatura Mexicana por la Universidad Nacional Autónoma de México, imparte actualmente asignaturas on $\mathrm{cl}$ Colegio de Literatura Dramática y Teatro de la UNAM en las áreas de Dramaturgia Mexicana, Latinoamericana, Rusa y Europea, Teoría Dramática y Teorías Escénicas. Entre sus trabajos de crítica e investigación teatral destacan títulos como Teatro adentro al descubierto (1997), Se buscan dramaturgos (2002) o Escena mexicana de los noventa (2003), así como su colaboración en la colección Teatro mexicano. Historia y dramaturgia (1992).
\end{abstract}

\section{LA TEATRALIDAD ACTUAL DE LA PASIÓN EN IZTAPALAPA}

\author{
ARMANDO PARTIDA TAYZÁN
}

\title{
RESUMEN
}

Desde el puesto privilegiado que la Semana Santa tiene en el imaginario nacional trataremos de hacer un recorrido descriptivo de los episodios más relevantes de la representación actual de la Pasión en Iztapalapa. La epidemia de cólera ocurrida en 1833 hizo resurgir esta escenificación que, por otra parte, tuvo inicialmente un sentido ritual, para poder estabilizar al mundo. Así se hizo necesaria la occisión ritual del propio Salvador, quien con su muerte venía a salvar a la humanidad; al igual que lo hicieran los ancestros de los moradores actuales de Iztapalapa en la ceremonia del Quinto Sol y del Fuego Nuevo.

Estamos sin duda ante una de las escenificaciones religiosas más populares y arraigadas de entre las que se llevan a cabo a lo largo del año en diversas poblaciones del país.

\section{PRESENT DAY HISTRIONICS OF THE PASSION IN IZTAPALAPA}

\section{ABSTRACT}

With the privileged position Holy Week enjoys in the national consciousness, an attempt to describe the most relevant episodes in the present representation of the Passion in Iztapalapa will be made. The cholera epidemic in 1833 inspired the reappearance of this re-enactment, whose origins lie in the ritualistic, so as to be able to stabilise the world and put a stop to the destruction caused by cholera. In this way, the ritual occision of the Saviour himself was essential, his death saving humanity. The ancestors of Iztapalapa's present-day inhabitants did it the same way in the Fifth Sun and New Fire ceremony.

This is without doubt one of the most popular and deep-rooted religious re-enactments amongst those taking place in different locations around the country throughout the year.

La Semana Santa en México ocupa un lugar dominante en el imaginario nacional, por ser ésta una de las representaciones etnodramáticas que más encontramos en diversas regiones del país, tanto en Guerrero, como entre los coras, los yaquis y mayos, o en el centro del país, pero la más conocida es, sin duda alguna, la representación de la Pasión en Iztapalapa, que anualmente se celebra en el Distrito Federal.
No obstante haber sido prohibidas muchas de las representaciones teatrales con tema religioso, en la segunda mitad del siglo XVIII, algunas pudieron pasar la censura. Entre éstas encontramos la escenificación de la Pasión, que a lo largo del período novohispano alcanzó una gran difusión ${ }^{1}$; misma, que debido a esa prohibición poco a poco fue extinguiéndose a fines de ese siglo. La Independencia, 
paradójicamente, vino a restaurar muchas de las costumbres populares, en particular las relacionadas con las representaciones religiosas que se efectuaban en los días de los santos patronos de los pueblos indios y mestizos.

En algunos casos, como en el relacionado con el reinicio de la representación de la $\mathrm{Pa}$ sión en Iztapalapa, éste se debió a un hecho fortuito: en 1833 la cólera morbus azotó y diezmó a la población de este poblado y, en agradecimiento de que hubiese terminado, los lugareños reiniciaron la tradición de la celebración de la Semana Santa. En la actualidad, tal representación es considerada como un hecho que ha tenido lugar «en medio de un paganismo que pretendía invocar y revivir uno de los capítulos más trascendentes de la fe cristiana, pero que se estructuró en textos ajenos a los bíblicos y hasta en publicaciones profanas ${ }^{2}$, de allí que ésta se haya convertido hoy en la escenificación religiosa más popular y más grande de entre las que tienen lugar a lo largo del año en diversas regiones del país.

I. Su inicio es el Domingo de Ramos, cuando de la calle Aztecas de este antiguo poblado de Iztapalapa, sito en el sudeste de la ciudad de México, y hoy integrado al Distrito Federal, parten cientos de actores: nazarenos; penitentes; viejos, jóvenes y niños, vestidos a la usanza del redentor, y cargando una cruz, al igual que éste -para expiar alguna culpa o pagar una «manda» por un favor recibido-, y vecinos del lugar, quienes en un tiempo se dirigían a la parroquia local, donde un cura oficiaba la misa y bendecía las palmas traídas en procesión al compás del monótono ritmo del tamborín y del flautín. Palmas procedentes de los estados de Oaxaca y Puebla, y proporcionadas por los mayordomos, encargados de ello. Luego todos se dirigían al santuario de la Cuevita, donde tiene lugar la entrada triunfal de Jesús a Jerusalén.

La representación de los sucesos bíblicos del Jueves Santo se iniciaba en el Santuario de la Cuevita pues, aunque la Iglesia no participaba oficialmente en la celebración, por ser ésta organizada por los vecinos y las autoridades locales, el «señor cura» oficiaba las misas, bendecía los ramos y confesaba a los participantes, en tanto el Obispo pronunciaba la elocución por motivo de Semana Santa; es decir: dejaban hacer a los vecinos lo que por más de 153 años habían escenificando. Más recientemente, debido al carácter mundano que ha tomado la representación, además del cambio de curas que ha tenido lugar, la iglesia local efectúa dentro de su ámbito -la nave de la iglesia y el atrio-jardín bardado- su propio festejo de Semana Santa, del todo religioso-cristiano, independientemente del gran espectáculo que tiene lugar en el exterior, a su alrededor.

Dicha elocución del Jueves Santo -previa a la procesión-, en la actualidad tiene lugar en el Jardín Cuitláhuac, donde luego se representa asimismo la Última Cena, la Ceremonia del Lavato-

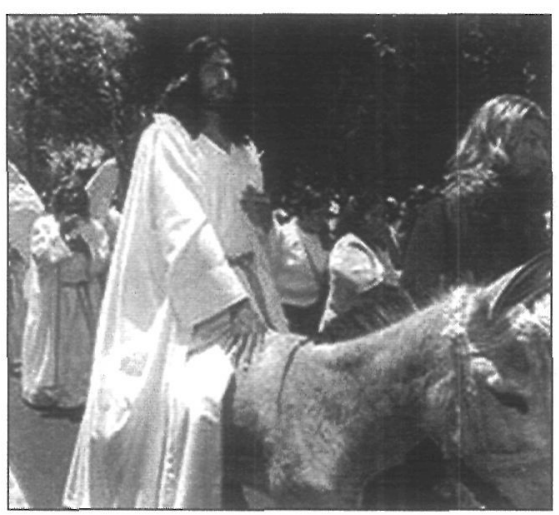

Domingo de Ramos. Iztapalapa 2006 rio, la Oración del Huerto, la Aprehensión y el Juicio de Jesús; esta última escena, seguramente es la más teatral por las vestimentas y los participantes.

La representación, inicialmente de carácter religioso, se ha tornado, con el correr de los años, en un verdadero espectáculo teatral de masas, presenciado por los creyentes locales y por cientos de miles de turistas locales, extranjeros que observan «con atención y respeto esta nueva versión del Drama del salvador; contenidos por una valla de uniformados», y que conmovidos por la condena insultan a Judas Iscariote y ríen por «la indumentaria de los centuriones, flacos como quijotes» ${ }^{3}$; perdiendo así su naturaleza inicial.

«Un cuarteto de centuriones muy sui generis, da inicio al drama, y desde lo alto del Gran Sanderín tocan la marcha dragona», en tanto que «En la explanada, unos quinientos penitentes -con túnicas moradas y un cirio en la mano-forman un cuadro para dar paso a Jesús y sus doce discípulos» ${ }^{4}$. Luego tiene lugar la escena de la Última Cena, los Doce Apóstoles ocupan sus asientos en la mesa, colocada sobre una de las plataformas, construidas ex profeso, para luego pasar al Lavatorio y después a la Oración en el Huerto de los Olivos, donde el Nazareno es aprehendido.

En la escenificación del Primer Concilio participan Caifás, Anás, Herodes y Judas, quien ofrece en venta a Jesús, escuchándose a través de los altoparlantes la tonada local del barrio, del habla de los habitantes de este poblado. Los parlamentos que intercambian los protagonistas del drama provienen de manuscritos que han pasado de mano en mano, de generación en generación, por lo que no coinciden con las escrituras sagradas, al haberse transformado -según el gusto de los participantes-, con el correr de las décadas. Por otra parte, los cambios que sufre el texto en el momento de su interpretación, ya sea por
2

Marcela Rubín, «Cinco millones costará representar la pasión en Iztapalapa», Excelsior, 26 de marzo de 1986.

3

ld.

4.

Id.
La teatralidad actual de la Pasión en Iztapalapa

ARMANDO PARTIDA TAYZÁN 


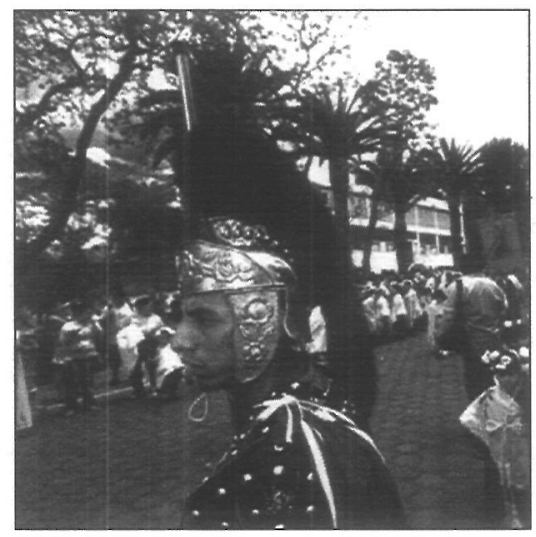

Soldado romano. Pasión de Iztapalapa 2004. habérseles olvidado, por repetirlos sin saber a ciencia cierta lo que están diciendo, o por modificarlos en el último momento, constituyen realizaciones diferentes cada vez. Lo mismo ha ocurrido con los episodios. La trama se ha visto fuertemente contaminada por elementos ajenos contemporáneos o por agregarle otras escenas, como la que va de la Loma del Cerro de la Estrella a la casa de Anás. Así, de un lado a otro, transcurre la Presentación y Juicio de Jesús, seguidos por los miles de espectadores durante todo el día y parte de la noche.

Los actores-organizadores consideran que esta representación tiene lugar en el «teatro más grande del mundo» $y$, efectivamente, así lo es: los desplazamientos de cuatro kilómetros, el paisaje urbano combinado con el natural, cada día más exiguo, junto con las enormes estructuras levantadas, constituyen un grandioso ámbito escénico, con un gran despliegue de escenografía, vestuario y utilería, además de los cientos de actores, quienes se desplazan en medio de ese paisaje urbano, que gracias a la teatralidad que está teniendo lugar y la muchedumbre que rodea al espectáculo, ha perdido tanto su temporalidad como su espacialidad originales.

El Viernes Santo es cuando tiene lugar el tercer Concilio, efectuándose un recorrido por los ocho barrios del pueblo de Iztapalapa con los tres mil actores que regularmente participan: los penitentes y los nazarenos que colman las calles. Sin duda alguna, en este día es cuando la representación llega a su máxima espectacularidad. Se inicia la procesión del Vía Crucis, que culmina en el Gólgota -el Cerro de la Estrella-, regularmente cubierto con los cientos de cruces llevadas, literalmente a cuestas, por los nazarenos participantes, y clavadas por éstos. Construidas de acuerdo a su gusto personal, y según su penitencia, cada una es de diverso tamaño y peso; además, los nazarenos van coronados con flores amarillas entrelazadas, cubriendo las espinas con las que también se castigan. Sólo la corona del Nazareno lleva al descubierto las largas espinas de cinco centímetros de largo, que hacen sangrar la frente y cabeza de éste.

Pero antes ha tenido lugar el Juicio, y a las 12:35h los clarines han anunciado que Jesús ha sido condenado y va a decidirse qué castigo darle. Mientras tanto, Herodes bebe de una copa de metal de las artesanías nacionales y muerde displicentemente un racimo de uvas artificiales, de plástico, tendido en un sofá, dispuesto en uno de los templetes. Y Pilato -llamado «presidente de la República»- desde otro observa con gravedad sentado en su trono. Jesús es de nuevo llevado de la casa de Herodes a la de Caifás. La mayoría, de los más de dos y medio millones de espectadores se agitan tratando de seguir la procesión, en tanto otros se conforman con verla al paso, a través de periscopios caseros, manufacturados con envases de cartón que antes contenían leche, jugos y otros productos.

En esta Pasión no hay resurrección. La representación concluye con la muerte de Judas, quien se cuelga de inmediato -después de la crucifixión-, a un lado del Calvario, en la cúspide del Cerro de la Estrella. El actor que interpreta este rol, que ya lo ha representado varias veces, como los otros participantes los demás papeles, ya está inquieto por mostrarnos su arte, perfeccionado a lo largo de años para recrear este personaje, para poder exhibir la larga lengua morada de cerdo que le saldrá de la boca por entre los dientes, cuando finalmente penda de la soga.

Todos los actores han sido rigurosamente seleccionados, pues deben dar el «tipo». De apóstol: jóvenes de aspecto agradable. De Judas: ¡chaparro, corpulento, y de fácil palabra y mímica! La mujer de Pilato: guapa, atractiva, un poco generosa en sus atributos físicos, para poder mostrarse pecaminosa $y$, en ese día, debe estar particularmente «bella». Barrabás: fortachón, grande, tosco, etc. Al mismo tiempo, todos deben contar con «voz clara, potente y sonora, además de capacidad histriónica», no obstante la utilización de la electrónica, pues sus parlamentos son emitidos por medio del micrófono.

La elección anual de quien representará a Jesús es la parte más importante de la preparación previa de la organización de la representación. Este debe contar con atributos físicos para poder resistir los kilómetros de recorrido cargando una cruz de 80 kilos, más las caídas, ya que no son actuadas, al igual que los golpes de los soldados «romanos». Sin embargo, los requisitos más importantes son los de haber nacido en el lugar y ser hijo de padres también oriundos del barrio. Por otra parte, debe probar su calidad moral, no tener ningún vicio, pero sí reputación intachable, ser puro y nunca haber tenido novia, para poder representar dignamente al Salvador.

Éste es elegido con seis meses de anticipación, mismo tiempo que toma su entrena- 
miento físico con largas caminatas. Desde el mes de enero se inicia su «retiro espiritual»y comienza a dejarse crecer la melena, que muchas veces es teñida -esa semana- de castaño claro (o rubio), para tener un parecido externo al Jesús de las estampas religiosas.

Un lugar muy especial ocupa la confección - la renovación del vestuario de todos los participantes, con telas brillantes y de colores chillones, junto con terciopelos y galones dorados y plateados; a lo que se agregan pelucas y un grueso y burdo maquillaje, que a pleno sol se escurre de inmediato. De esta manera salen travestidos los cientos de romanos, apóstoles, judíos y samaritanos en esta gigantesca manifestación espectacular de la popular Pasión y muerte del hijo del Hombre.

De hecho nos encontramos con una representación teatral que en la actualidad ha perdido tanto su origen como su significado religioso-cristiano, pues casi ninguno de los espectadores es capaz de explicar la razón de tal acontecimiento; por ello, no es nada raro escuchar en los labios de algún joven, responder, al preguntársele sobre el motivo de la crucifixión: "Por defendernos de los judíos, según dicen en la televisión. ¿No?».

Alrededor de los escenarios se encuentran miles de puestos con toda suerte de baratijas, mercancías y fritangas. Los gritos de los anuncios, de las cumbias y «quebraditas", vomitados estruendosamente por los altoparlantes de comercios y ferias con juegos mecánicos, compiten con el recitado torpe de los diálogos de Pilato, Herodes y Jesús, también trasmitidos por potentes aparatos de sonido; sumándose a éstos los clarines de los heraldos y la música de viento de la banda municipal en las pausas dramáticas.

II. La escenificación de la Pasión y la celebración de la Semana Santa tienen lugar en muchas otras partes del mundo católico, e incluso algunas tienen una tradición de siglos, por lo que se han convertido, además de ser una manifestación de dolor y expiación para los creyentes, en una atracción turística por sus valores estéticos y escénicos. ¿Pero qué es lo que atrae y tiene de particular la Pasión en Iztapalapa?

Mecánicamente se la ha explicado como una celebración religiosa de carácter sincrético: cristiano-pagano, en la que han sido substituidas las deidades del Panteón Azteca por las figuras de las Santas Escrituras; a partir de lo que se ha dicho del teatro evangelizador del siglo XVI, surgido en la Nueva Es- paña, una vez concluida la Conquista armada. El caso es que esta escenificación se reinició después de la Independencia, al término del primer tercio del siglo XIX. Es por ello que dicha teoría del sincretismo no podemos aceptarla del todo.

¿Qué es lo que en el fondo podemos encontrar en relación a esto? Para podernos explicar el

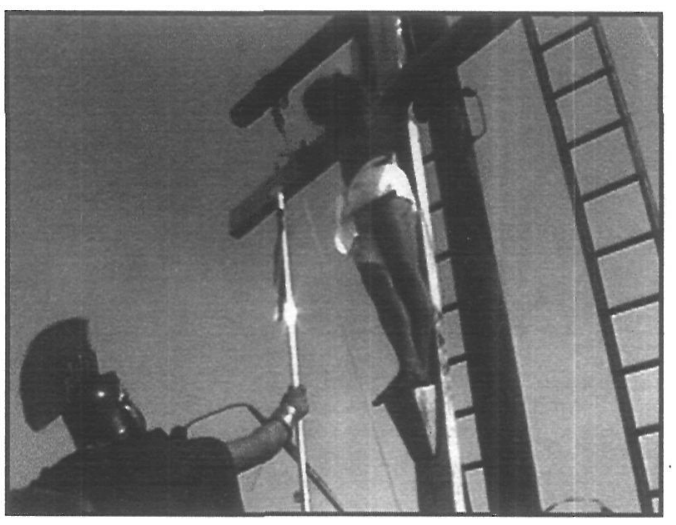

Crucifixión. Pasión de Iztapalapa 2004. contenido y la razón de ser de esta representación teatral, para poder determinar su esencia, frente a las otras celebraciones del mundo católico, tenemos que recurrir a algunas de las descripciones de los rituales prehispánicos.

Fray Bartolomé de las Casas nos dice, en su Apologética Historia Sumaria, que

Cuando los españoles entraron en la Nueva España, que fue año de 1518, por hebreo, comenzaron el año las gentes dela en primero de marzo, porque por no alcanzar bisiesto no podía comenzar de allí a otro año, y así había de ir cada año variando. Acabados los diez y ocho meses, los dichos cinco días irregulares eran muy gran solemnidad cada uno dellos, donde se celebraban muy regocijadas fiestas con grandes sacrificios y ceremonias hasta que entraba el año siguiente. El postrero día de cada mes era fiesta general en toda la tierra, y de gran solemnidad en cierto día que era postrero de cierta hebdómada de años que tenían, y este día era el postrero día de cincuenta y dos años, que era la hebdómadas.

Como podemos percatarnos, el fin del siglo mexica coincidía con la celebración de la Pascua, época en la que se efectuaban ceremonias de carácter propiciatorio y ritual:

En la ciudad de México y en todas sus provincias hacían esta ceremonia, conviene a saber, que por mandamientos de los pontífices y sacerdotes mataban todos los fuegos de los templos y de todas las casas, para esto salían ciertos ministros del gran templo de México e iban dos leguas de allí por la calzada, a una villa o ciudad llamada Iztapalápan, y subíanse en un collado y mogotes o serrejón que llamaban vixachtla, donde había un templo con quien tenía el gran rey Moctezuma muy arraigada devoción' 6 .

La referencia a que hace de las Casas es sobre la ceremonia del Fuego Nuevo, en la que el pueblo de Iztapalapa y el Cerro de la Estrella jugaban un papel muy importante.
5

Fray Bartolomé de las Casas, Apologética Historia Sumaria, edición de Edmundo O'Gorman, México UNAM, 1976, vol. 2.

6

Ibid.
La teatralidad actual de la Pasión en Iztapalapa

$\overline{\text { ARMANDO PAR'TIDA TAYZÁN }}$ 


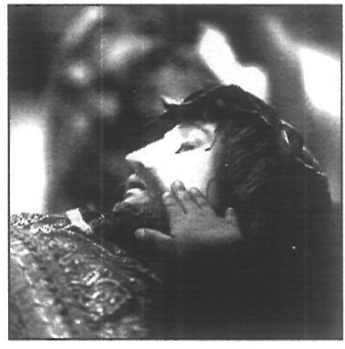

Cristo yacente. Pasión de Iztapalapa 2004.

7

Joseph de Acosta, Historia natural y moral de las Indias, edición de Edmundo O'Gorman. México, FCE, 1962.

\section{8}

Fray Diego Durán, Historia de las Indias de Nueva España, apud. Miguel León Portilla, Antología de Teotihuacan a los aztecas, fuentes e interpretaciones históricas, México, UNAM, 1983.

9

Acosta, op. cit., págs. 271-275.
A su vez, Joseph de Acosta, al describir las celebraciones a Tezcatlipoca, nos proporciona información sobre la ritualidad mexica, también estrechamente relacionada con la escenificación de la Pasión en Iztapalapa:

...comenzaban su celebración a nueve de mayo, y acabábase a diez y nueve. En la mañana del último día, sacaban sus sacerdotes unas andas aderezadas, con cortinas y cendales, de diversas maneras. Tenían estas andas tantos asideros cuantos eran los ministros que las habían de llevar, todos los cuales salían embijados de negro con unas cabelleras largas trenzadas por mitad de ellas con unas cintas blancas, y con unas vestimentas de librea del ídolo. Encima de aquellas andas ponían el personaje del ídolo señalado para este oficio, que ellos llamaban semejanza del dios Tezcatlipoca, y tomándolo en los hombros lo sacaban en público, al pie de las gradas?.

Por otra parte, en la festividad consagrada a Quetzalcóalt, celebrada en una fecha anterior, encontramos una descripción más detallada del mismo tipo de rito propiciatorio:

La fiesta de este ídolo celebraban los naturales a tres de febrero, un día después de nuestra Señora de la Purificación, según nuestro ordinario. La cual solemnidad se solemnizaba de esta manera: cuarenta días antes de este día los mercaderes compraban un indio, sano de pies y manos, sin mácula ni señal alguna, que ni fuera tuerto, ni con nube en los ojos; ni cojo, ni manco, ni contrahecho; no lagañoso, ni baboso, ni desdentado; no había de tener señal ninguna de que hubiese sido descalabrado, ni señal de divieso, ni de bubas, ni de lamparones. En fin, que fuese limpio de toda mácula.

A este esclavo compraban para que vestido como el ídolo, le representase aquellos cuarenta días. Y antes que le vistiesen, le purificaban, lavándolo dos veces en el agua de los dioses. Después de lavado y purificado, le vestían a la mesma manera que el ídolo estaba vestido, según y como queda referido de él, poniéndole la corona, el pico de pájaro, la manta, el joyel, las calcetas y zarcillos de oro, el braguero, la rodela, la hoz. Este hombre representaba vivo a este ídolo aquellos cuarenta días. El cual era servido y reverenciado como a tal; traía su guardia y otra mucha gente que le acompañaba todos los días 8 .

Como podemos darnos cuenta, para tal efecto se compraba un esclavo en el mercado, que debería estar limpio de cualquier irregularidad en la piel, para luego ser purificado y vestido con la indumentaria del dios. Mediante la propiciación y el travestismo, el hombre se transformaba en el dios en cues- tión, ocupando su lugar y las vestimentas que los simbolizaban. Lo mismo ocurría en la celebración consagrada al dios Tezcatlipoca, como explicaba fray Diego de Durán.

Si por una parte nos encontramos con un proceso de selección de quien representará a Jesús, con un período preparatorio con la misma duración de cuarenta días, por otra, el proceso de travestismo, de apropiación de la persona del dios, resulta muy semejante, además de que en principio se persigue el mismo objetivo.

Otras coincidencias muy cercanas, advertidas ya por el padre Acosta, guardan estrecha relación con algunos de los momentos de la escenificación de Iztapalapa, ya descritos anteriormente:

Después de puesto el ídolo en sus andas, tenían por todo aquel lugar gran cantidad de pencas de maguey, cuyas hojas son anchas y espinosas. Puestas las andas por dentro del circuito del patio, llevándose adelante de sí dos sacerdotes con dos braceros o incenciarios, inciensando muy a menudo el ídolo (...) Toda la demás gente que estaba en el patio, volviéndose en rueda hacia la parte donde iba el ídolo, llevaban todos en las manos unas sogas de hilo de maguey, nuevas, de una braza con un ñudo al cabo, y con aquellas se disciplinaban dándose grandes golpes en las espaldas de la manera que acá se disciplinan el Jueves Santo. Toda la cerca del patio y las almenas estaban llenas de ramos y flores, también adornadas y con tanta frescura, que causaban gran contento\%.

De las descripciones anteriores, efectivamente se desprende que en las celebraciones a Quetzalcóatl, pero en particular del Fuego Nuevo y del Quinto Sol pueden encontrarse elementos escénico-rituales muy cercanos a los de la escenificación teatral de la Semana Santa en Iztapalapa:

El Año Nuevo, celebrado en marzo con sacrificios y ceremonias propiciatorias. El recorrido de dos leguas, del templo Mayor al pueblo de Iztapalapa, hasta el Cerro de la Estrella. La inclusión de la topografía. La selección de un joven que representará al dios Tezcatlipoca, al cual debería asemejársele mediante el uso de su indumentaria ritual, que contenía los diversos símbolos distintivos. Como explicaba Acosta,

...la fiesta del ídolo Tezcatlipuca era muy solemnizada. Venía esta fiesta por mayo, y en su calendario tenía nombre toxcatl. Pero la misma cada cuatro años concurría con la fiesta de la penitencia, en que había 
indulgencia plenaria y perdón de pecados. Sacrificaban este día un cautivo, que tenía la semejanza del ídolo Tezcatlipuca ${ }^{10}$;

mismo que además debía ser puro, seleccionándose entre muchos otros candidatos, para luego ser recluido en penitencia y así poder ser digno de representar al dios.

Luego venía la procesión y la participación de quienes a su vez realizaban sacrificios con las espinas de maguey; como forma ritual propiciatoria, practicada para sangrarse con esas espinas; rito, que por otra parte, se practicaba cotidianamente, a diversas horas del día o de la noche. Actos propiciatorios muy cercanos a los que tienen lugar en la Pasión en Iztapalapa: la presencia de los penitentes en la celebración del Domingo de Ramos; además del ofrecimiento de las palmas, que luego son consagradas durante la misa, y que vienen a ocupar el lugar de las ofrendas florales, tan generalizadas para agradar a los dioses; además de las penitencias de los nazarenos el Viernes Santo.

Por todo lo anteriormente expuesto, no es raro el que, cuando los cronistas actuales se refieran a esta escenificación, efectúen una transposición mecánica entre los ritos cristianos y los indígenas. Esto no tiene nada de raro, pues los propios cronistas misioneros del XVI al hacer el relato, al interpretar los ritos de los mexicas, tomaron como modelo su propio imaginario cultural y religioso (como podemos percatarnos en las extensas citas aquí incluidas), ya que, si efectuamos un análisis somero de su imaginario, a partir de su visión del mundo y su ideología, nos encontraremos que los frailes, al igual que los demás cronistas, repitieron su propio modelo ideológico al interpretar al mundo prehispánico. De allí que surja la pregunta, cuando se habla del sincretismo pagano-cristiano: ¿a qué dios o dioses se están substituyendo a través del personaje de Jesús? Partiendo de esa explicación mecanicista es difícil encontrar respuesta.

Como podemos ver, nos encontramos ante el hecho de que, durante la evangelización de los indios de la Nueva España, en el siglo XVI, no podemos hablar sólo de que haya tenido lugar un proceso de sincretismo cristianopagano, sino también de la identificación de una mística religiosa propia del poblador del altiplano mexicano. De manera que los indios pudieron fácilmente manifestarse a través de las escenificaciones cristianas, sin que tuviera lugar una substitución de sus rituales, habiendo encontrado en las manifestaciones teatrales de los misioneros los mismos componentes externos y los mecanismos internos de su propio drama, que igualmente tenían «un sentido y un fin en sí mismo»; como en este caso concreto de la Pasión, donde el Salvador moría sacrificado como uno más de sus dioses; desde su perspectiva religiosa-cultural, por haber llegado a término su ciclo, por lo cual se hacía necesaria su muerte, es decir: su sacrificio; al igual que en esta escenificación popular.

En la representación actual de la Pasión en Iztapalapa, nos encontramos conque la epidemia de cólera, que ocurriera en 1833, hizo resurgir esta escenificación que, por otra parte, tuviera inicialmente un sentido ritual, para poder estabilizar al mundo y no siguiera destruyéndose por la cólera. Así se hizo necesaria la occisión ritual del propio Salvador, quien con su muerte venía a salvar a la humanidad; al igual que lo hicieran los ancestros de los moradores actuales de Iztapalapa en la ceremonia del Quinto Sol y del Fuego Nuevo. Por otra parte, no hay que olvidar, que con estas ceremonias llegaba a término el ciclo vital de los dioses, por lo que había que sacrificarlos, travestidos en los cautivos seleccionados para ello, para así dar comienzo a un nuevo ciclo y no a una resurrección, como en el caso original de la Pasión bíblica, que no tiene lugar en la teatralización de Iztapalapa.

Es evidente que con el correr de los siglos se perdió el significado ritual original prehispánico al imponerse la ideología cristiana; sin embargo, su imaginario resurgió con el reinicio de la escenificación de la Pasión en este poblado. Con el dominio del catolicismo, la memoria colectiva trasladó a un segundo lugar el antecedente ritual de las ceremonias que se celebraban en ese lugar; en tanto, la anécdota y el relato de la Pasión de Jesús se arraigó aquí; resemantizando con ello el significado sagrado del lugar de la representación.

Lo paradójico de todo esto es que, en la época actual, ambos contenidos: pagano-religiosos, se han ido borrando, al predominar el espectáculo teatral, por la monumentabilidad que ha ido tomando la escenificación del pasaje bíblico. Aunque siguen prevaleciendo en esencia los mismos motivos religiosos, durante la realización de la dramatización dominan los aspectos de la escenificación, de la teatralidad, sobre los estrictamente religiosos. De hecho aquí tenemos uno de los ejemplos más puros del «teatro tosco» de Peter Brook, mismo que seduce al «público», compuesto por los miles de espectadores que año con año son convocados por esta representación en Iztapalapa.

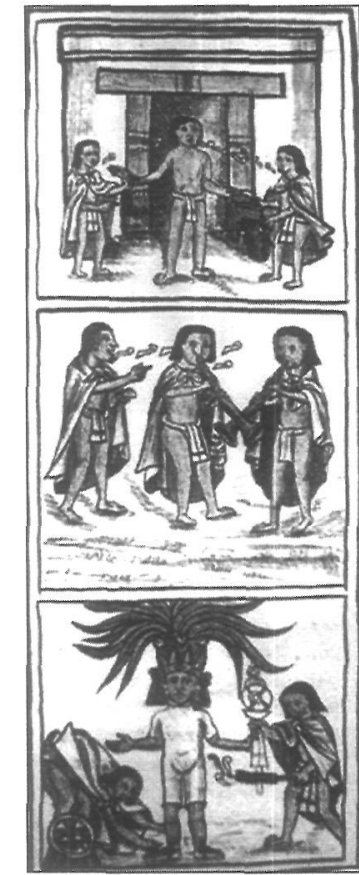

Fray Bernardino de Sahagún, pintura del Códice florentino.

10

Ibid., 275

La teatralidad actual de la Pasión en Iztapalapa

ARMANDO PARTIDA TAYZÁN 


\section{BIBLIOGRAFÍA CITADA}

Acosta, Joseph de, Historia natural y moral de las Indias, edición de Edmundo O’Gorman. México, FCE, 1962.

Casas, fray Bartolomé de las, Apologética Historia Sumaria, edición preparada por Edmundo O'Gorman. 2 vols., México UNAM, 1976.

"Con estrecheces, la Pasión en Iztapalapa», Excelsior, 28.03.1986.
León-Portilla, Miguel, Antología de Teotibuacan a los aztecas, fuentes e interpretaciones históricas, México, UNAM, 1983.

Horcasitas, Fernando, El teatro nábuatl: épocas novohispana y moderna, México, UNAM, 1974.

Rubín, Marcela, «Cinco millones costará representar la pasión en Iztapalapa», Excelsior, 26.03.1986. 